\title{
Estimation of economic feasibility of development of national measurement standards
}

\author{
Pavel Neyezhmakov ${ }^{1, a}$, Alexander Prokopov ${ }^{1}$ \\ ${ }^{1}$ National Scientific Centre "Institute of Metrology", Mironosytska Str. 42, 61002 Kharkiv, Ukraine.
}

\begin{abstract}
Résumé. Au cours des dernières années, il ya une croissance soutenue des investissements en technologies de mesure, entraînant une intensification des recherches dans le domaine des problèmes économiques de la métrologie. Parmi les secteurs les plus importants de la recherche sont les aspects économiques de la création et le fonctionnement des normes nationales. Le rapport énonce les principes de base de l'approche à ce problème, développé dans le NSC "Institut de métrologie" (Ukraine). Il est proposé de comparer deux options de comportement économique selon l'élément supérieur de la hiérarchie de mesure dans tous les pays - normes nationales. La comparaison est basée sur le critère de coût minimum de fournir une traçabilité à l'unité de la grandeur physique avec la précision requise pour l'économie. Cette traçabilité peut être réalisé de deux façons: d'abord - de son propre étalon primaire, deuxième - à partir d'une norme étrangère ou internationale. L'algorithme mathématique pour évaluer la faisabilité économique de la création d'un étalon primaire nationale est présentée, ainsi que pour évaluer le temps de récupération des investissements nécessaires pour le créer. La validité de l'algorithme est confirmée par l'exemple des normes nationales de l'Ukraine création.
\end{abstract}

\section{Economics of metrology problem. Short history.}

In recent years the intensification of researches in the field of economic problems of metrology is observed, due to the steady growth of investments in measuring technologies, observed in a number of countries in the world [1], and the need to analyze the effectiveness of such investments.

Among the main reasons that encourage modern researches of mutual influence of economy and metrology, there can be noted the processes of globalization, the signing of the Arrangement on Mutual Recognition of National Measurement Standards and of Calibration and Measurement Certificates Issued by National Metrology Institutes (CIPM MRA) [2], etc. Such studies are currently conducted in many countries, as well as at the level of international organizations. In the National Institute of Standards and Technology (NIST) in the United States the studies on the influence of quality of metrological support on the specific economic industries in the USA were carried out (from enhancing the accuracy of determining the amount of cholesterol in medicine to improving computer security in information technologies). The estimated ratio of income to expenses for metrology in a given branch of industry fluctuated from 4 to 249 (with an average of 47) [3].

Similar studies have been carried out in Germany, Great Britain, France, Ukraine, and other countries [4-9].

\footnotetext{
a pavel.neyezhmakov@metrology.kharkov.ua
}

Studies were made [4] during 2000-2002 with the support of EU for analyzing the economic role of measurements and testing in modern Europe. It was founded that expenses on metrology amounting to $1 \%$ of the EU GDP (all forms of measurements were included) boosted the GDP by $2.7 \%$. In other words, for each Euro spent on metrology, the economy receives an income of about 3 Euros.

Studies supported by the BIPM [5] (see also a survey conducted on the initiative of the International Organization of Legal Metrology (OIML) [6]) indicate that metrology contributes significantly through the reducing technological barriers to trade and creating favorable conditions for manufacturers.

This is achieved primarily through the traceability to the International System of Units (SI). The national standards after international comparisons guarantee that the calibrations traceable to them are comparable. This comparability and consistency are of critical importance for the development of economy, science and social life.

The methods used in the reports cited above were generally based on expert evaluations, various statistical data, the results of surveys, and standard computational formulas from economics. Thus, most of these results are more qualitative than quantitative in nature. In this regard, an attempt to develop a quantitative theory of the influence of the precision characteristics of standards on the economic performance of manufacturers and consumers of a given product $[7,8]$ is of interest. 
The analysis of considered publications shows that the theoretical aspects of the interrelation of metrology and economics are still insufficiently studied. There is still no general theory which can provide a quantitative description of the mutual relationship of metrology and economics and to be based on the most acceptable from the standpoint of economics ways of developing a government metrological system. The situation is understandable since the task of the joint consideration of the interaction of metrology and economics is a distinctly systems problem, which requires a systematic approach, the general theory of which remains insufficiently developed.

\section{Economics of metrology in NSC "Institute of Metrology" researches}

In this connection, a quantitative approach being developed in the studies of the NSC "Institute of Metrology" is proposed. But the aim of these studies [9] is not the global impact of metrology on economics, the narrower task of analyzing the economic aspects of the creation and functioning of the top element of the measurement hierarchy in the country - national standards - is set.

The basis of our approach is the idea of comparing two (or more) options of economic behavior according to the considering link of metrological system. Thus stated, it is a component of the general problem discussed above. In this case, the comparison is carried out on the criterion of minimum costs on the realization of the unit of physical quantity with the necessary accuracy for the country. In this case, the possible costs for creating a national primary standard (NPS) for any type of measurements (first option) are compared with the potential costs for the calibration of secondary standard of the country abroad in case of absence of NPS, accumulated over the time corresponding to the term of operation of the primary standard (second option). The accuracy requirements for the process of traceability of the unit of physical quantity to the primary standard for the reviewed options are considered equal. The option with the lowest costs is considered to be economically feasible. When implementing this approach, it is assumed that the characteristics of the developed (used) standards will be guided by already achieved global indications. If a task is set to exceed the world level, it is necessary to solve the more complex general problem of the global impact of metrology on economics of the country (within a systematic approach that enable to take into account the economic impact on all levels of application of measurement instruments (MI)).

\section{Mathematic model and its applications}

A mathematical model, which is the basis of economic feasibility evaluation methodology, looks as follows. It is considered that traceability to the primary standard of the unit of measurement is provided either by the NPS that has passed international comparisons and has CMCs in KCDB database, or - in cases where NPS has not been created, - by a reference (secondary) standard of the country (RS). It is considered that such RS is calibrated abroad (the foreign standard will be the source of the traceability for its CMCs).

When determining the annual expenses for the top element of the measurement hierarchy, $E_{M N P S}$ and $E_{M R S}$ expenses for the maintenance (operation) of NPS or RS, respectively, $E_{C R S}$ expenses for calibration of RS abroad, and $E_{C r N P S}$ expenses for the creation of NPS are taken into account. $R_{P N P S}$ and $R_{P R S}$ revenues from performing calibrations using NPS or RS, respectively, are also taken into account.

As for the possible $E_{I R S}$ expenses for the improvement of $\mathrm{RS}$, as well as for $E_{I C N P S}$ expenses for international comparisons of NPS, they are not included to the annual balance, but are accounted separately in the overall balance for the total time of operation of the standard.

Within the considered model, the state of the highest link of the system of metrological support of a certain kind of measurements for the current time reduces to one of three possible states that differ in the structure of expenses:

1) NPS is present and used in the calibration chain; the current (or annual) expenses balance in this state is determined by $E_{M N P S}$ and $R_{P N P S}$;

2) NPS is absent and is not being developed, the functions of NPS are performed by RS (the current expenses balance is determined by $E_{M R S}, E_{C R S}, R_{P R S}$ );

3) NPS is absent, but the works for its creation have already been started, while the functions of NPS are still temporary performed by RS (the expenses balance is determined by $\left.E_{M R S}, E_{C R S}, E_{C r N P S}, R_{P R S}\right)$.

Taking into account the mentioned states, the current (annual) balance "expenses minus revenues" $B_{i}$ for $i$-type of measurements can be expressed as:

$$
B_{i}=\left\{\begin{array}{l}
B_{i}^{S}=E_{i M N P S}-R_{i P N P S}-\text { for state } 1 \\
B_{i}^{A}=E_{i M R S}+E_{i C R S}-R_{i P R S}-\text { for state } 2 \\
B_{i}{ }^{W}=E_{i M R S}+E_{i C R S}+E_{i C r N P S}-R_{i P R S}-\text { for state } 3
\end{array}\right.
$$

Let $N_{\text {Cr }}$ years are needed to create NPS. The created standard is used in international comparisons and operated $N_{O}$ years until it worns out and the time comes to replace it with a new one. The expenses for the maintainance of the standard of the considered type of measurements during $N_{C r}+N_{O}$ years can be represented as follows:

$$
B_{i}{ }^{W} \cdot N_{C \mathrm{r}}+B_{i}^{S} \cdot N_{O}+E_{I R S}^{*}+E_{I C N P S}-
$$

NPS has been developed (option 1);

$$
B_{i}{ }^{A} \cdot\left(N_{C \mathrm{r}}+N_{O}\right)+E_{I R S}-
$$

NPS has not been developed (option 2),

where $E^{*}{ }_{I R S}, E_{I R S}$ - total expenses for the improvement of RS for the options 1 and 2, respectively.

The creation of NPS makes sense from the economical point of view only in case the expenses during $N_{C r}+N_{O}$ years for the maintenance of the highest element of the measurement hierarchy will be lower than ones for the case where NPS has not been created. This condition using the formula (2) can be expressed as:

$$
B_{i}^{W} . N_{C \mathrm{r}}+B_{i}^{S} . N_{O}+E_{I C N P S}+E_{I R S}^{*}<B_{i}^{A} .\left(N_{\mathrm{Cr}}+N_{O}\right)+E_{I R S}
$$


The stronger the inequality (3) is, the greater the economic feasibility for the creation of NPS. Costs payback time of creating the standard we obtain after transferring to the equality in (3), replacing $N_{O}$ with $t$ and solving the resulting equation:

$$
t=\frac{\left(B_{i}{ }^{W}-B_{i}{ }^{A}\right) N_{C \mathrm{r}}+E_{I C N P S}+E_{I R S}^{*}-E_{I R S}}{B_{i}{ }^{A}-B_{i}{ }^{S}}
$$

From the moment of time $t$, defined by the formula (4), the inequality (3) becomes true. In later moments of time, this inequality increases, reflecting an increase in cost savings for the maintenance of the highest element of the measurement hierarchy for the considered type of measurements. It is obvious that the savings obtained for $N_{C r}+N_{O}$ years are determined by the difference between the right and left side of inequality (3).

Accounting of expenses for international comparisons results in increase of costs payback time for the creation of the standard by an amount proportional to the ratio of total expenses for international comparisons to the annual expenses for the calibration of the reference standard abroad (for the case, when there is a reference standard, and the own primary standard is absent).

This method can also be used to validate the economic feasibility of improving NPS, if during its operation there arises a need in reduced uncertainty of calibration from the standard.

NPS that had been working before this need arised, will not be able to meet the new requirements in such a case, so this situation can be considered as a signal for a new selection of the optimal option in conditions with the absence of NPS. That is, it can be considered to address the question of what is exactly feasible in this situation: to improve the existing NPS, or to create a RS with the required metrological characteristics? For making such a choice the above algorithm is extremely suitable, using which in a given situation the word "creation" shall be replaced by "improvement", and all the expenses and revenues in the formulas (1)-(4) to select taking into account the raised costs of the component parts and all works due to the higher accuracy requirements. Since during the improvement the certain elements of replaced NPS can be used, it is necessary to take this into account when determining the total costs for the improvement of this NPS.

As an example, we will show the results of evaluating the economic feasibility of costs for creating the national primary standard of the unit of luminous flux. Expenses and benefits were evaluated in Ukrainian hryvnia (UAH). In accordance with the calculations performed, the payback time for the creation of the standard was only 4.6 years, and the expected cost savings over the lifetime of the created standard were about 1 millions UAH. Exactly these performance indicators have played a crucial role in the decision on the creation of this national standard, which is currently one of the most frequently used standards of Ukraine.

\section{Conclusions}

In conclusion, we once again focus on the conditions of the application of the method presented in the article, which requires information on the expenses and revenues only on the level of standards. The purpose of this method is in evaluating of economic feasibility of creating the national primary standard that ensures the necessary accuracy of measurements in conditions where one can choose from two opportunities. The first opportunity is to create an own national primary standard, the second one is not to create own standard, and to get the unit of physical quantity with the necessary uncertainty from a foreign primary standard. As already mentioned, the accuracy characteristics of traceability of the unit of physical quantity and the costs for it realization thus shall be the same for both opportunities.

If there is no a standard abroad that can provide the necessary uncertainty of receiving the unit of measurement, the proposed method is not applicable. In this case, the task of evaluating of economic feasibility of creating an own national primary standard shall be solved on the basis of the analysis of expenses and revenues of the metrological works throughout the whole chain - from primary standard to working MI in specific sectors of the economics. It is clear that such a task requires separate consideration which goes beyond the scope of this article.

\section{References}

1. Communication from the Commission to the European Parliament, the Council, the European Economic and Social Committee and the Committee of the Regions. Brussels, 06.05.2013, http://eur-lex.europa.eu/LexUriServ/ LexUriServ.do?uri=SWD:2013:0249:FIN:en:pdf

2. Mutual Recognition of National Measurement Standards and of Calibration and Measurement Certificates Issued by National Metrology Institutes. BIPM, October 1999, http://www.bipm.org/en/cipm$\mathrm{mra} / \mathrm{mra}$ online.html

3. Summary of NIST Laboratory Economic Impact Studies, http://www.nist.gov/director/planning/summary-studies.cfm

4. G. Williams, "The assessment of the economic role of measurement and testing in modern society," European Measurement Project Report, July 2002, http://www.bis.gov.uk/assets/bispartners/nmo/docs/n ms/economics of measurements july2002.pdf

5. M. MacDonald e.a. "Potential Economic Impact of the CIPM Mutual Recognition Arrangement," KPMG Report submitted BIPM, 2002, http://www.bipm.org/ utils/en/pdf/ KPMG report.pdf

6. J. Birch, "Benefit of Legal Metrology for the Economy and Society," CIML Report, 2003, www.oiml.org?publication/E/birch/E002-e03.pdf

7. T. Usuda, "Study on economic impact of equivalence of measurement standards," BIPM KCDB Newsletter, No. 16, 1-2 (2011).

8. T. Usuda and A. Henson, "Economic Impact of Equivalence of Measurement Standards," NCSLI Measure, 7, No. 1, 62-70 (2012).

9. P. I. Neyezhmakov, A. V. Prokopov, "Evaluating the Economic Feasibility of Creating National Primary Standards," Izmerit. Tech., No. 4, 3-6 (2014), in Russian. 